\title{
A Trimethylguanosine Synthase 1-like (TGS1) homologue is implicated in vernalisation and flowering time control
}

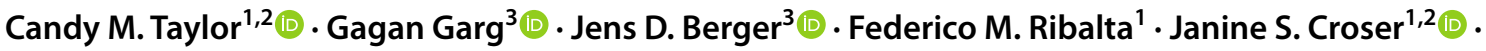

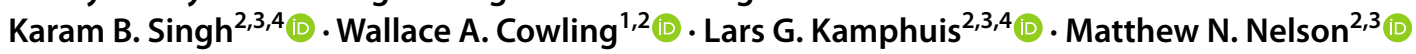

Received: 19 February 2021 / Accepted: 6 July 2021 / Published online: 13 July 2021

(c) The Author(s) 2021

\begin{abstract}
Key message A plant-specific Trimethylguanosine Synthase1-like homologue was identified as a candidate gene for the $e f l$ mutation in narrow-leafed lupin, which alters phenology by reducing vernalisation requirement.

Abstract The vernalisation pathway is a key component of flowering time control in plants from temperate regions but is not well understood in the legume family. Here we examined vernalisation control in the temperate grain legume species, narrow-leafed lupin (Lupinus angustifolius L.), and discovered a candidate gene for an ethylene imine mutation (efl). The efl mutation changes phenology from late to mid-season flowering and additionally causes transformation from obligate to facultative vernalisation requirement. The efl locus was mapped to pseudochromosome NLL-10 in a recombinant inbred line (RIL) mapping population developed by accelerated single seed descent. Candidate genes were identified in the reference genome, and a diverse panel of narrow-leafed lupins was screened to validate mutations specific to accessions with efl. A non-synonymous SNP mutation within an S-adenosyl-L-methionine-dependent methyltransferase protein domain of a Trimethylguanosine Synthase1-like (TGS1) orthologue was identified as the candidate mutation giving rise to efl. This mutation caused substitution of an amino acid within an established motif at a position that is otherwise highly conserved in several plant families and was perfectly correlated with the efl phenotype in $F_{2}$ and $F_{6}$ genetic population and a panel of diverse accessions, including the original efl mutant. Expression of the TGSI homologue did not differ between wild-type and efl genotypes, supporting altered functional activity of the gene product. This is the first time a TGSI orthologue has been associated with vernalisation response and flowering time control in any plant species.
\end{abstract}

\section{Introduction}

Prolonged exposure to cold temperature represents an important stimulus for the promotion of flowering in many annual and biennial plants of temperate origins. This stimulus,

Communicated by Henry T. Nguyen.

Wallace A. Cowling

wallace.cowling@uwa.edu.au

1 UWA School of Agriculture and Environment, The University of Western Australia, Perth, WA 6009, Australia

2 The UWA Institute of Agriculture, The University of Western Australia, Perth, WA 6009, Australia

3 Agriculture and Food, Commonwealth Scientific and Industrial Research Organisation, Floreat, WA 6014, Australia

4 Centre for Crop and Disease Management, Curtin University, Bentley, WA 6102, Australia known as vernalisation, is one of several environmental signals that are used by plants, together with endogenous cues, to align reproductive development with favourable biotic and abiotic conditions. The mechanisms through which plants perceive vernalisation are well-known to vary between families of plants (Bouché et al. 2017; Ream et al. 2012). Considerable progress has been made towards identifying the central integrator genes within the vernalisation pathway of cool-season legumes over the past decade. An FT orthologue ( LanFTcl) was recently implicated as the main integrator gene for vernalisation response in narrow-leafed lupin (Lupinus angustifolius L.), and large deletions of up to $5162 \mathrm{bp}$ within the promoter region of the gene were found to be responsible for the $K u$ and $J u l$ phenotypes (Nelson et al. 2017; Taylor et al. 2019). Similarly, FT orthologues from the $F T a$ clade have been identified as candidate/causal genes for major vernalisation-responsive QTLs in Medicago truncatula (Jaudal et al. 2013; Laurie et al. 2011), white lupin 
(L. albus) (Rychel et al. 2019), chickpea (Cicer arietinum) and its wild progenitor, C. reticulatum (Ortega et al. 2019).

In contrast, little is known about the identities and roles of upstream genes within the vernalisation pathway in legumes. Only one study to date has reported the discovery of an upstream gene within the vernalisation pathway in the Fabaceae. An orthologue of the Vernalisation 2 polycomb group protein gene (MtVRN2) which regulates FT in Arabidopsis thaliana (hereafter Arabidopsis) through chromatin modification (Gendall et al. 2001) was found to repress the expression of MtFTal in M. truncatula (Jaudal et al. 2016). The molecular mechanisms through which this is achieved and whether this repression is direct or indirect remain unclear (Jaudal et al. 2016). The only other major finding regarding upstream genes has been the notable absence of well-known repressors of $F T$ from the model Arabidopsis, such as FLC, in almost all legume species (Hecht et al. 2005, 2011), with the possible exception of soybean (Glycine max) (Jung et al. 2012).

Narrow-leafed lupin is an annual cool-season legume with a native distribution throughout the Mediterranean basin and Northern Africa (Gladstones 1970). It was domesticated as a pulse crop in the mid-twentieth century and has since become a valuable component of sustainable agricultural systems in Australia and northern European countries, such as Poland, Russia, and Germany (Hondelmann 1984; Lucas et al. 2015). This has largely been attributed to its capacity to improve soil fertility through symbiotic nitrogen fixation and the mobilisation of soil-bound phosphorus (Lambers et al. 2013), which, together with its traditional role as a break crop, enables the simultaneous benefits of reduced fertiliser input costs in addition to opportunities to reduce the severity of weeds, pests, and diseases that affect cereals (Harries et al. 2015).

Successful adaptation of annual plants to their environment depends on appropriate phenology (Nelson et al. 2010). The main strategy for adapting narrow-leafed lupins to short-season agricultural environments has been strong directional selection for early, vernalisation-insensitive phenology during breeding (Berger et al. 2012a, b). The dominant $K u$ early flowering time locus has been widely adopted throughout Australia to enable drought-escape in the warm Mediterranean climate experienced in the north of the Western Australia (WA) wheatbelt region, which to this day accounts for approximately $70 \%$ of Australian lupin production (ABARE 2018; Gladstones and Hill 1969). In parallel, the allelic Julius ( $\mathrm{Jul}$ ) locus was adopted in northern Europe for summer production and the timely maturation of crops before the onset of winter (Mikołajczyk 1966; Taylor et al. 2019).

The widespread use of $K u$ and $J u l$ by breeders since their independent discoveries in the 1960s has drastically reduced phenological variation among elite varieties and limited the broader adaptive capacity of narrow-leafed lupin. Such varieties are not adapted to cool, longer season Mediterraneantype environments where partial vernalisation would be an advantage (Berger et al. 2012a, b). Modelling suggests that yield improvements of 13-16\% (approximately $390-480 \mathrm{~kg} /$ ha) are possible in narrow-leafed lupin in long-season environments by delaying flowering two to three weeks relative to $K u$ varieties (Chen et al. 2017), reinforcing the need to increase the phenological diversity of the crop. Understanding the genetic background of flowering time is an important precursor for successfully incorporating novel phenological variation into elite domesticated varieties. In particular, knowledge of the vernalisation pathway is critical as it is the single most influential regulatory mechanism for flowering time control in narrow-leafed lupin crops (Gladstones and Hill 1969; Rahman and Gladstones 1972; Taylor et al. 2020a, b).

The $e f$ locus represents a valuable yet under-utilised source of genetic variation for reduced vernalisation requirement in domesticated narrow-leafed lupin. It is a recessive mutation that was initially derived in the 1960s through mutagenesis of the Swedish variety, Borre, with $0.24 \%$ aqueous ethylene imine (Gladstones 1977). The mutation causes a shift from an obligate to facultative vernalisation requirement, where vernalisation accelerates the transition to reproductive growth but is no longer essential (Gladstones 1982; Landers 1995). The resulting flowering time phenotype is roughly 10-14 days earlier than $k u$ wild types and two to three weeks later than $K u$ vernalisation-insensitive types under long-season environmental conditions (Gladstones 1982). Although the first efl variety, named Chittick, was believed to have a phenology close to the optimal for many mid-high rainfall environments at the time of its release in the 1980s (Gladstones 1982), it was outcompeted by earlier flowering $K u$ varieties with important agronomic advances, including resistance to phomopsis stem and pod blight (Diaporthe toxica) (Cowling et al. 1988, 1987; Cowling and Wood 1989). Since then, efl has only been bred into one other Australian variety, Wandoo (Cowling 1999; Cowling 2020), and its integration into modern breeding lines alongside other key traits would be aided by molecular markers to improve the efficiency of selection.

Here we report the discovery of a plant-specific Trimethylguanosine Synthase 1-like (TGS1) orthologue as a strong candidate gene for efl and propose that a G/A SNP transition within its coding sequence (CDS) produces an amino acid substitution that interrupts a conserved motif critical for substrate binding. TGS1 has significant roles in posttranscriptional regulation and processing of a wide variety of RNA (e.g. small nuclear (sn) RNA, small nucleolar (sno) RNA, telomerase RNA and selenoprotein mRNAs) across all kingdoms (Chen et al. 2020; Girard et al. 2008; Mouaikel et al. 2003, 2002; Wurth et al. 2014). This is the first time a 
TGS1 homologue has been linked to vernalisation response within the plant kingdom.

\section{Methods}

\section{Genetic population development}

$F_{2}$ and $F_{6}$ bi-parental mapping populations were developed from a cross between narrow-leafed lupin varieties, Chittick (maternal parent) and Geebung (paternal parent). Chittick is homozygous for the efl mutation (Gladstones 1982) and has a facultative vernalisation requirement, while Geebung has an obligate vernalisation requirement (Berger et al. 2012a). Geebung has a putative $E f$ genotype and was chosen as the late-flowering parent in this RIL population because it has a lower coefficient of co-ancestry with Chittick than other lateflowering varieties (e.g. Marri, Uniharvest, and Uniwhite) on the basis of pedigree information (Cowling 2020) and Euclidean distances based on $>10,000$ DArTseq SNP markers (Mousavi-Derazmahalleh et al. 2018).

Seeds of Chittick and Geebung were germinated on Petri dishes lined with moistened filter paper and vernalised in the dark at $4{ }^{\circ} \mathrm{C}$ for 21 days. Seedlings were then planted in steam-pasteurised soil mix (UWA Plant Bio Mix, Richgro Garden Products Australia Pty Ltd) in $7 \times 7 \mathrm{~cm}(750 \mathrm{~mL})$ pots and grown at $20^{\circ} \mathrm{C}$ with natural photoperiod (ranging 10-12 h) in a phytotron at The University of Western Australia (UWA), Perth, Australia ( $31^{\circ} 59^{\prime} 04.8^{\prime \prime} \mathrm{S}, 115^{\circ} 49^{\prime} 09.5^{\prime \prime}$ E), in 2016. Plants were watered daily and fertilised fortnightly with water-soluble NPK fertiliser with micronutrients (Peters Excel, Everris NA Inc.) at a rate of $250 \mathrm{mg} /$ pot. After crossing and maturation of hybrid seed, one $F_{1}$ seed was germinated, vernalised, and grown in a pot in the phytotron as described above. PCR-based assays of the LaIND_026 molecular marker (5' GGACCATTGTGCCTT GGG 3'; 5' GAAGTGGCAGAACTGGTTGG 3') (Kamphuis et al. 2015), for which Chittick and Geebung have contrasting alleles ( $\sim 200$ and $\sim 180$ bp amplicons, respectively), were used to confirm this plant was a true $F_{1}$ hybrid (data not shown). More than $550 F_{2}$ seed were harvested from this $F_{1}$ individual at maturity.

An accelerated single seed descent (aSSD) approach utilising an optimised ratio of red to far-red light for legumes (Croser et al. 2016) was used to rapidly progress $330 F_{2}$ individuals to the $F_{6}$ generation. In each selfing generation, seeds were firstly germinated in Jiffy- $7 \AA$ pellets and vernalised at $4{ }^{\circ} \mathrm{C}$ for 21 days to satisfy the requirements of obligate vernalisation genotypes, thereby ensuring rapid and synchronised flowering and seed production in all RILs. Seedlings were then transplanted to $750-\mathrm{mL}$ pots and cared for as described above. Plants were grown at $24{ }^{\circ} \mathrm{C}$ (day) $/ 20^{\circ} \mathrm{C}$ (night) under natural light supplemented with light-emitting diode arrays (AP67,
L-series, Valoya ${ }^{\circledR}$ lights, Helsinki, Finland) to create a 20-h photoperiod (Croser et al. 2016). Four generations of aSSD occurred over a period of 13 months (average generation time of 13.5 weeks, inclusive of vernalisation treatment), and a total of $185 F_{5}$-derived $F_{6}$ RILs were harvested.

\section{Phenotyping $F_{2}$ and $F_{6}$ mapping populations}

Segregation of flowering time was assessed in $200 F_{2}$ individuals, $10 F_{1}$ hybrids, and 20 biological replicates of each parent (Chittick and Geebung) from mid-May to late-August 2017 in a phytotron located at UWA. This trial occurred in parallel to the $F_{6}$ recombinant inbred line (RIL) population development using separate $F_{2}$ individuals. Seeds were germinated in Jiffy-7® pellets and vernalised for 40 days in the phytotron at $15{ }^{\circ} \mathrm{C}$. This vernalisation treatment was designed to enhance the difference in flowering time between Chittick and Geebung under mild vernalisation conditions (JD Berger, unpublished data). Seedlings were transplanted into pots following vernalisation treatment (as described above) and placed within a randomised block design. The temperature of the phytotron was subsequently increased to $21^{\circ} \mathrm{C}$ to prevent further vernalisation. Flowering was scored when the first flower was fully opened (i.e. displayed an erect standard petal) or displayed a deepening pink pigmentation on the petals, both of which are indicative of anthesis (Dracup and Kirby 1996). A Chi-square goodness-of-fit test was used to evaluate whether segregation of efl:Efl phenotypes conformed to the expected 1:3 ratio for a Mendelian gene in an $F_{2}$ population.

The $F_{6}$ RIL population was similarly phenotyped in a phytotron at UWA under natural daylight (ranging from 10 to $11.5 \mathrm{~h}$ ) in 2018 . Three $F_{6}$ seeds per RIL (i.e. biological replicates) were sown if sufficient seeds were available; however, 17 RILs had sufficient seed for only one or two biological replicates (Online Resource 1). Biological replicates of Chittick $(n=3)$ and Geebung $(n=12)$ were also phenotyped. Germination, vernalisation, transplanting, and phenotyping within an incomplete block design were as described for the $F_{2}$ population. Each RIL was assigned to a phenotypic category based on the average flowering time of biological replicates (the 'efl' group with similar flowering to Chittick and the 'Efl' phenotype group with similar flowering time to Geebung), and a Chi-square goodness-of-fit test was used to evaluate the expected 1:1 segregation of efl:Efl phenotypes in this RIL population.

\section{Genotyping the $F_{6}$ RILs population and its parents}

\section{DArT-seq genotyping of the $F_{6}$ population and its parents}

Freeze-dried leaf material from the $185 F_{6}$ RILs and population parents was provided to Diversity Arrays Technology 
Pty Ltd (Canberra, Australia) for gDNA extraction and subsequent DArTseq ${ }^{\mathrm{TM}}$ genotyping-by-sequencing (hereafter DArTseq) (Sansaloni et al. 2011), as described by Mousavi-Derazmahalleh et al. (2018), to produce SNP and presence/absence variation (PAV) markers. The physical coordinates of all SNP and PAV markers were determined by BLAST of the DArTseq marker sequence to the Tanjil reference genome assembly (Hane et al. 2017) using a minimum sequence identity threshold of $80 \%$ and an e-value of $5 e-07$.

\section{Whole-genome re-sequencing of Chittick and Geebung}

DNA of Chittick and Geebung was extracted from young leaves using a CTAB method (Doyle and Doyle 1990). DNA samples were then submitted to Novogene (Hong Kong) for $2 \times 150$ bp Paired-End library preparation using the default recommendations in the NEBNext ${ }^{\circledR}$ DNA Library Prep Master Mix Set for Illumina ${ }^{\circledR}$ kit and whole-genome re-sequencing at approximately $10 \times$ coverage using Illumina ${ }^{\circledR}$ sequencing by synthesis technology. Raw reads were checked for quality and adapter content using FastQC (Andrews 2010). Adapter trimming was carried out using cutadapt (parameters: -format fastq -overlap 10 -times 3 -minimum-length 25) (Martin 2011). The raw sequencing data generated have been deposited in the Sequencing Read Archive (SRA; BioProject ID PRJNA674415).

\section{Genotyping the LanFTc1 promoter region in Chittick and Geebung}

Whole-genome re-sequencing reads for Chittick and Geebung were aligned to the wild-type ( $k u$ LanFTcl promoter sequence from accession P27255 (GenBank ID KT862491) (Nelson et al. 2017). This alignment was used to establish the LanFTcl promoter genotype of Chittick and Geebung and confirm whether the efl locus was distinct from a series of large deletions within this region that underlies the $K u$ and $J u l$ alleles for early flowering time in domesticated narrowleafed lupin.

\section{Linkage and QTL mapping}

SNP and PAV DArTseq markers were filtered for quality control purposes. Markers with $>50 \%$ call rate, a homozygous allele frequency between 0.2 and 0.8 (SNPs only), and a Chi-square $P$ value $>1 \mathrm{e}-05$ were retained. SNPs with $>15 \%$ heterozygosity were additionally removed. All markers were then phased according to the parental genotypes, and any markers with an ambiguous phase were represented in both phases. A qualitative marker representing the efl phenotype was created for the purposes of linkage map construction and QTL mapping. Homozygous efl genotypes were assigned to $F_{6}$ RILs with an early average flowering time of 71-78 days, while homozygous $E f$ genotypes were assigned to late-flowering time averages of 84-95 days. Missing values were allocated to RILs with intermediate phenotypes (79-83 days to flowering) (Online Resource 1). The qualitative efl phenotype-derived marker and SNP/PAV markers were encoded in the same way with ' $A$ ' representing the maternal $e f$ genotype, ' $B$ ' representing the paternal $E f$ genotype, and '-' representing missing or heterozygous values.

A linkage map for the $F_{6}$ RIL population was created using the ASMap (Taylor and Butler 2017) and Rqtl (Broman et al. 2003) packages for $R$ computing software. The following settings were implemented: the Kosambi method for genetic distance calculation; a count function to minimise the sum of recombination events; a $P$ value threshold of $1 \mathrm{e}-18$ for clustering markers; and a maximum of $15 \mathrm{cM}$ between linked markers. Marker genotyping for three $F_{6}$ RILs (CxG_F6_100, CxG_F6_101, and CxG_F6_155) was identified as problematic based on the high frequency of missing values $(n>650)$ and double crossovers they introduced ( $n=16$ to 28 ), and was therefore removed from further analysis. Two $F_{6}$ RILs (CxG_F6_215 and CxG_F6_218) had 98\% similarity in genotype; these two RILs were recorded as a single consensus genotype. Clusters with $\leq 5$ markers were discarded, as were linkage groups comprising only ambiguously phased markers whose respective mirrored partners mapped appropriately within larger linkage groups.

QTL mapping was conducted within the ASMap and Rqtl packages (Broman et al. 2003; Taylor and Butler 2017). An interval mapping approach implementing the expectation-maximisation (EM) algorithm was used to detect QTLs for mean days to flowering in the $F_{6}$ RILs. A genome-wide logarithm of the odds (LOD) threshold of 2.95 was used to declare QTL at a 95\% confidence interval. This threshold was established via permutation testing with 1000 permutations.

\section{Defining the eff locus and its candidate genes}

FGenesh (v2.6) (Solovyev et al. 2006) was used to identify predicted open reading frames (ORF) within a mapped region of interest sourced from an improved PacBio assembly for Tanjil (G Garg, LG Kamphuis, R Foley \& K Singh, unpublished data). Organism-specific gene-finding parameters were implemented for Glycine max, which was selected as the closest legume relative of narrow-leafed lupin. Sequencing reads from Chittick, Geebung, and additional 43 accessions (G Garg, LG Kamphuis, R Foley \& $\mathrm{K}$ Singh, unpublished data) were aligned to the region of interest using Bowtie (v2.3.4) (Langmead and Salzberg 2012), and variants were called using SAMtools ( $\mathrm{Li}$ et al. 2009). The predicted CDS of a candidate gene was used 
as a query sequence for BLASTn against the NCBI nonredundant (nr) nucleotide sequence database to determine a putative functional annotation. Phylogenetic analysis of the candidate gene family was conducted via CLUSTAL Omega (v1.2.4; https://www.ebi.ac.uk/Tools/msa/clustalo/) alignment of protein sequences from narrow-leafed lupin, 16 other papilionoid legumes, 12 diploid species from five other angiosperm families, and yeast (Saccharomyces cerevisiae) (Online Resource 2). Protein sequences for the phylogenetic analysis were identified through BLASTp against the NCBI and Unité de Recherche Génomique Info (URGI) non-redundant protein sequence databases. Based on this alignment, a neighbour-joining phylogenetic tree without distance corrections was constructed using CLUSTAL Omega and visualised using FigTree (v1.4.3).

\section{Validating an efl candidate gene and putative causal SNP}

\section{Co-segregation of the efl phenotype and SNP mutation}

PCR primers (5' CATCTGTAGTGGCAATGCGC 3' and 5' AAGGCCTTTGCTCACTCCAA 3') were designed to amplify a 567-bp gDNA fragment within the efl candidate gene in which a unique SNP of interest with a G/A transition was approximately central. PCR amplification was conducted according to reaction and cycling programme details provided in Online Resource 3. PCR amplicons were submitted to Macrogen (Seoul, South Korea) for bi-directional Sanger sequencing. SNP genotypes were tested for cosegregation with efl phenotype in the $F_{2}$ and $F_{6}$ bi-parental populations and a diverse set of 40 wild and 49 domesticated accessions (Online Resources 4 and 5).

\section{Predicted protein composition, domains, and structure}

Haplotypes for the candidate gene CDS were established by comparison of SNP genotypes observed within Chittick, Geebung, Tanjil, 43 accessions with re-sequencing data, and three other key narrow-leafed lupins, including: N4229 (the original efl mutant), Borre (the variety used in mutagenesis to derive efl), and Wandoo (the only other commercial variety with $e f l$ ). SNPs within the CDS of these latter three accessions were genotyped via bi-directional Sanger sequencing (Macrogen: Seoul, South Korea) of five PCR amplicons targeting polymorphic exons within the candidate gene (Online Resources 3 and 6). Translated amino acid sequences for each unique haplotype were aligned using CLUSTAL Omega (v1.2.4; https://www.ebi.ac.uk/Tools/ $\mathrm{msa} / \mathrm{clustalo} /$ ) and were examined in InterPro Scan (https:// www.ebi.ac.uk/interpro/result/InterProScan/) to determine whether any substitutions interrupted functional protein domains. Finally, 3D protein models were constructed based on the $3 \mathrm{gdh} .1$.A template using the SWISS-MODEL automated protein structure homology-modelling server (https:// swissmodel.expasy.org/).

\section{Gene expression analyses}

Seeds of Chittick and Geebung were imbibed in Milli-Q water for $6 \mathrm{~h}$ and were either immediately sown (non-vernalised treatment) or incubated in Petri dishes at $4{ }^{\circ} \mathrm{C}$ for 21 days (vernalisation treatment) before sowing. Imbibition was staggered so that the vernalised treatment had accumulated approximately the same thermal time (expressed as the number of degree-days with a $0{ }^{\circ} \mathrm{C}$ baseline temperature) as the non-vernalised treatment at the time of sowing. All plants were grown in a phytotron at UWA under natural daylight (11.5-13.75 h). An average diurnal ambient temperature regime of $21{ }^{\circ} \mathrm{C}$ (day) and $18{ }^{\circ} \mathrm{C}$ (night) was used to prevent further vernalisation. The four uppermost fully emerged leaves were snap-frozen in liquid nitrogen when plants had reached the 4-, 8-, 12-, and 16-leaf stages and at flowering (in the case of vernalised plants) or when the primary inflorescence began to demonstrate signs of floral meristem reversion (in the case of non-vernalised plants).

RNA extraction, cDNA synthesis, and qPCR analyses were performed on three biological replicates according to the methods described by Taylor et al. (2016). Relative transcript abundance of the candidate gene was measured as the average threshold cycle $\left(C_{T}\right)$ based on two primer pairs specific to different exons within each gene (Online Resource 7) and was subsequently normalised against the previously validated reference gene, Ubiquitin $C$ (UBC) (Taylor et al. 2016). The final relative expression of the candidate gene was expressed as $40-\Delta C_{T}$. A value of 40 on this $\log _{2}$ scale is equivalent to the expression of the reference gene, while the raw $C_{T}$ value of the reference gene reflects the minimum value on the scale. ANOVA and Tukey HSD post hoc statistical tests were conducted on the $40-\Delta C_{T}$ values within $R$ software.

\section{Results}

\section{Flowering time distribution in bi-parental mapping populations}

Bi-parental mapping populations designed to study efl were developed from Australian narrow-leafed lupin varieties, Chittick (maternal parent; efl genotype) and Geebung (paternal parent; $E f$ genotype). Chittick flowered on average 15.6 days earlier than Geebung during the first phenotyping trial evaluating $F_{1}$ and $F_{2}$ progeny (Fig. 1a). Consistent with expectations for a recessive gene with Mendelian inheritance, the $F_{1}$ hybrids had an average flowering time 
equal to Geebung at 84.5 days and early ( $e f$-like) to late ( $E f-$ like) flowering times segregated in an approximate 1:3 ratio among $F_{2}$ individuals $\left(\chi^{2}[\mathrm{DF}=1, n=198]=0.17, P>0.05\right)$.

A difference of 9.1 days to flowering separated Chittick and Geebung in the second phenotyping trial evaluating the $F_{6}$ RIL population. Average flowering times in the $185 F_{6}$ RILs followed a bimodal distribution with the two modes centred on the two parents (Fig. 1b). For the purposes of statistical testing, RILs with 71-81 mean days to flowering were assigned to the efl-like phenotypic category $(n=87)$, and RILs with 82-93 mean days to flowering were assigned to the $E f$-like phenotypic category $(n=98)$. The number of progeny in each category conformed to the expected $1: 1$ ratio of efl:Efl $\left(\chi^{2}[\mathrm{DF}=1]=0.538, P=0.463\right)$.

\section{Linkage and QTL mapping localises efl to a 267-Kb region on NLL-10}

DArTseq genotyping of the $F_{6}$ RIL population and its parental varieties produced $2503 \mathrm{SNP}$ and 17,710 PAV molecular markers. Following stringent quality filtering and the mirrorphasing of 355 ambiguous markers, a total of 1248 SNP and
Fig. 1 Frequency of mean days to flowering for a 200 $F_{2}$ individuals and b $185 F_{6}$ recombinant inbred lines of narrow-leafed lupin (Lupinus angustifolius L.) segregating at the efl flowering time locus. The populations were derived from a single cross between varieties, Chittick (efl) and Geebung (Efl). The mean flowering times for the parental varieties are indicated by yellow and dark blue arrows, respectively. Dashed boxes in (a) highlight the 33 earliest and 32 latest flowering $F_{2}$ individuals whose DNA were combined into early and late bulk samples for genotyping
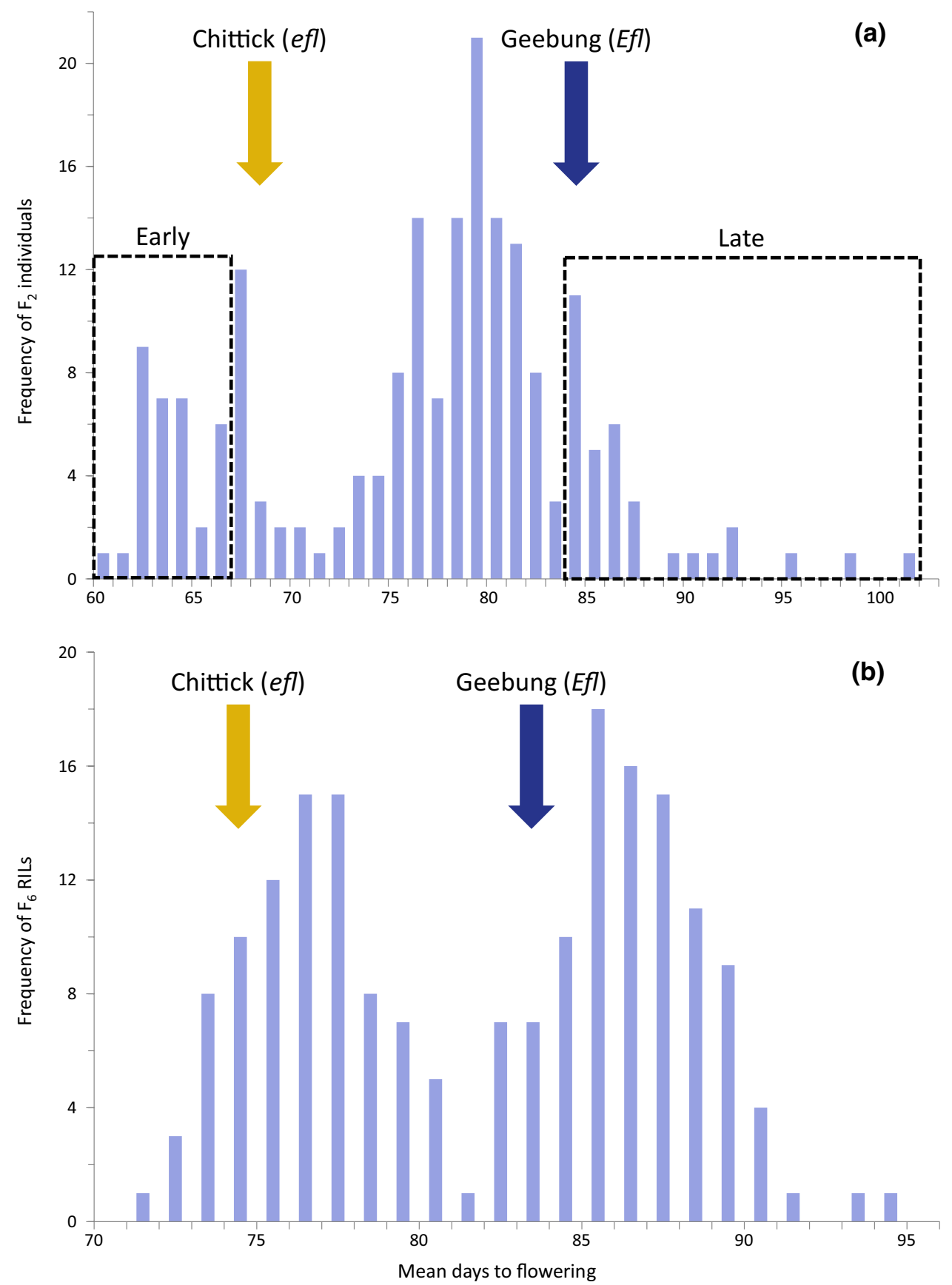
1473 PAV markers, plus one qualitative marker representing the efl phenotype, were retained for linkage mapping. This filtered set of markers adequately represented all pseudochromosomes except for NLL-11, NLL-15, and NLL-19, which each had five or less markers (Online Resource 8).

The preliminary linkage map based on the $F_{6}$ RIL population comprised 76 linkage groups, which far exceeded the number of haploid chromosomes $(n=20)$ for narrow-leafed lupin. Twenty-seven of these linkage groups were made up almost exclusively of ambiguously phased markers whose mirror partners mapped well in larger linkage groups. As a result, these artefactual linkage groups were discarded along with 10 small clusters with fewer than five loci.

The final linkage map incorporated 1035 SNP, 1279 PAV markers, and the efl phenotypic marker among the $181 F_{6}$ RILs (Online Resource 9). A total of 23 linkage groups were constructed, which largely represented 17 of the 20 haploid chromosomes for narrow-leafed lupin (Table 1). The size of individual linkage groups ranged from 0.6 to $131.8 \mathrm{cM}$, producing an overall map size of $781.2 \mathrm{cM}$.

Interval mapping resolved a major QTL for flowering time on the CxG_LG14 linkage group corresponding to pseudochromosome NLL-10. The QTL explained $81.95 \%$ of phenotypic variation for flowering time within the $F_{6}$ RIL population and achieved a maximum LOD score of 67.25 , which was centred on the qualitative efl phenotypic marker (Online Resource 9). The two DArTseq markers flanking the efl phenotypic marker (LangCGRIL_PAV04800, LOD 63.91; LangCGRIL_SNP1280, LOD 58.63) were separated by a $1.26 \mathrm{cM}$ genetic interval. However, a physical interval for the efl locus could not be initially established as LangCGRIL_PAV04800 was placed on NLL-06 (Online Resource 9), which suggested an assembly error within the region of interest in the published Tanjil reference genome (Hane et al. 2017). To overcome this apparent assembly error issue, sequences from the LangCGRIL_PAV04800
Table 1 Summary of the 23 linkage groups constructed in a genetic map of an $F_{6}$ RIL population $(n=181)$ derived between Australian narrow-leafed lupin (Lupinus angustifolius $\mathrm{L}$.) varieties, Chittick $(e f l, k u)$, and Geebung $(E f l, k u)$

\begin{tabular}{|c|c|c|c|}
\hline $\begin{array}{l}\text { Pseudochromosome represented } \\
\text { by linkage group }\end{array}$ & Linkage group ID & $\begin{array}{l}\text { Size of linkage group } \\
(\mathrm{cM})\end{array}$ & $\begin{array}{l}\text { Number of markers } \\
\text { in linkage group }\end{array}$ \\
\hline NLL-01 (top) & CxG_LG01 & 27.7 & 43 \\
\hline NLL-01 (bottom) & CxG_LG02 & 0.6 & 10 \\
\hline NLL-02 & CxG_LG03 & 80.7 & 227 \\
\hline NLL-03 (top) & CxG_LG04 & 1.7 & 12 \\
\hline NLL-03 (bottom) & CxG_LG05 & 86.3 & 188 \\
\hline NLL-04 (top) & CxG_LG06 & 41.5 & 80 \\
\hline NLL-04 (bottom) & CxG_LG07 & 23.3 & 43 \\
\hline NLL-05 & CxG_LG08 & 26.4 & 86 \\
\hline NLL-06 (top) & CxG_LG09 & 6.4 & 21 \\
\hline NLL-06 (bottom) & CxG_LG10 & 44.3 & 342 \\
\hline NLL-07 & CxG_LG11 & 17.5 & 84 \\
\hline NLL-08 & CxG_LG12 & 8.0 & 24 \\
\hline NLL-09 & CxG_LG13 & 77.2 & 92 \\
\hline NLL-10 & CxG_LG14 & 131.8 & 403 \\
\hline NLL-11 & $*$ & & \\
\hline NLL-12 (top) & CxG_LG15 & 4.4 & 12 \\
\hline NLL-12 (bottom) & CxG_LG16 & 12.5 & 55 \\
\hline NLL-13 & CxG_LG17 & 7.1 & 27 \\
\hline NLL-14 & CxG_LG18 & 75.0 & 198 \\
\hline NLL-15 & $*$ & & \\
\hline NLL-16 & CxG_LG19 & 26.4 & 72 \\
\hline NLL-17 (top) & CxG_LG20 & 5.5 & 36 \\
\hline NLL-17 (bottom) & CxG_LG21 & 0.7 & 8 \\
\hline NLL-18 & CxG_LG22 & 67.1 & 222 \\
\hline NLL-19 & $*$ & & \\
\hline NLL-20 & CxG_LG23 & 9.1 & 30 \\
\hline Total & & 781.2 & 2315 \\
\hline
\end{tabular}

The genetic map incorporated 2314 DArTseq molecular markers and one artificial marker representing efl phenotype within the RIL population developed in this study

Asterisks (*) denote incidences where a linkage group was not found to largely represent one of the 20 narrow-leafed lupin pseudochromosomes (Hane et al. 2017) 
and LangCGRIL_SNP1280 DArTseq markers were physically located within an improved PacBio assembly for Tanjil (G Garg, LG Kamphuis, R Foley, and K Singh, unpublished data). Both markers were located within a single contig from this assembly and consequently enabled a 267,160bp physical region of interest to be defined (GenBank ID MW218472).

\section{efl is not conditioned by a deletion in the LanFTc1 promoter}

LanFTc1 is a highly important central regulator of the vernalisation pathway in narrow-leafed lupin. To eliminate the possible involvement of LanFTc1 (NLL-10: $8,016,834-8,033,155)$, which is located approximately 2.5 $\mathrm{Mb}$ downstream of the efl locus NLL-10, we compared the 5, regulatory region of LanFTcl in Chittick and Geebung. Specifically, we sought determine whether both varieties share the wild-type LanFTc1 promoter $(k u)$ or whether Chittick possesses one of three large deletions (1208 bp; $1423 \mathrm{bp}, \mathrm{Ku}$; and $5162 \mathrm{bp}, J u l$ ), which are the only known polymorphisms associated with de-repressed LanFTcl expression, reduced vernalisation response, and early flowering time (Nelson et al. 2017; Taylor et al. 2019). High-throughput Illumina re-sequencing produced $42,338,865(\sim 13 \times$ depth coverage) and 34,313,565 ( 11× depth coverage $)$ short reads for Chittick and Geebung, respectively, which were mapped to the wild-type $(k u) L a n F T c 1$ promoter sequence (GenBank ID KT862491). Both parents shared the $k u$ wild-type allele, confirming that the efl phenotype is derived from an independent gene located upstream of LanFTc1 on NLL-10.

\section{Trimethylguanosine Synthase 1-like (LanTGS1) as a candidate gene for $e f$}

\section{Discovery of a strong positional candidate gene and underlying mutation}

The 267,160-bp region of interest was screened for transition polymorphisms (i.e. G/A and C/T SNPs) consistent with mutations commonly arising from alkylating agents, including ethylene imine (Griffiths et al. 2000; Verschaeve and Kirsch-Volders 1990). A total of 5242 and 10,738 SNPs with transitions were identified in Chittick and Geebung relative to the Tanjil reference genome, respectively. Of these transitions, 2507 were unique to Chittick and were subsequently compared to the SNPs present in the region of interest in a panel of 43 other resequenced narrow-leafed lupin accessions. Following this comparison, a single G/A SNP was found to be unique to Chittick within the predicted ORF of a gene comprising nine exons. This gene represented one of 40 ORFs annotated by FGENESH within the region of interest (Online Resource 10).
The candidate gene containing the unique G/A SNP was identified as Trimethylguanosine Synthasel-like (TGS1) (Lup005529.1, also referred to as TanjilG_05529; (Hane et al. 2017)). In contrast to all other eukaryotes, which possess a single $T G S 1$ orthologue, most diploid plant species thus far appear to contain two TGS1 homologues within their genomes (Mouaikel et al. 2003). The second LanTGS1 homologue (Lup008227.1, also referred to as TanjilG_08227; (Hane et al. 2017)) was located on pseudochromosome NLL-03. Translated sequences from both narrow-leafed lupin homologues (OIW10381.1 and OIW15651.1) shared S-adenosyl-L-methionine-dependent methyltransferase (SAM MTase; IPR029063) and RNA cap guanine-N2 methyltransferase domains (IPR019012), consistent with the methyltransferase function of TGS1 proteins. However, the presence of a WW domain (IPR001202), which is a defining feature of plant-specific TGS1 homologues, was exclusive to OIW 10381.1 and indicated that its associated gene Lup005529.1 is the plant-specific LanTGS1 homologue. Phylogenetic analysis of several papilionoid legumes and diploid species from five other agriculturally important angiosperm families revealed the two LanTGS1 homologues still share a very high degree of homology despite this difference. Interestingly, eukaryotic (i.e. non-plant-specific) TGS1 homologues do not appear to have been conserved beyond the genistoid clade within the papilionoid subfamily of legumes (Fig. 2). Given that plant-specific TGS1 homologues have roles in mediating chilling tolerance in Arabidopsis (Gao et al. 2017) and regulating apomixis (i.e. asexual reproduction via seeds) in Paspalum notatum (Siena et al. 2014; Colono et al. 2019), Lup005529.1 was considered worthy of further investigation as a candidate vernalisation-related flowering time gene for eff.

\section{Co-segregation of a transition mutation with the eff phenotype}

The G/A SNP unique to Chittick in Lup005529.1 was genotyped in the $F_{2}$ and $F_{6}$ bi-parental populations and a diverse range of wild and domesticated narrow-leafed lupins to confirm its co-segregation with efl phenotype. Within the $F_{2}$ population, DNA from the 33 earliest and 32 latest flowering $F_{2}$ individuals was combined into two separate bulk samples (Fig. 1a). The early (efl-like) bulk returned a homozygous A genotype identical to Chittick. Meanwhile, both alleles were detected in the late (Eflike) bulk. This was consistent with expectations that heterozygous and homozygous $\mathrm{G}$ genotypes should exhibit the dominant $E f l$ phenotype. Subsequent genotyping of individual $F_{2}$ plants within the late bulk confirmed the absence of homozygous A genotypes (Online Resource 4). Within the $F_{6}$ RIL population, 86 homozygous A (Chittick-derived), 96 homozygous $\mathrm{G}$ (Geebung-derived), and 


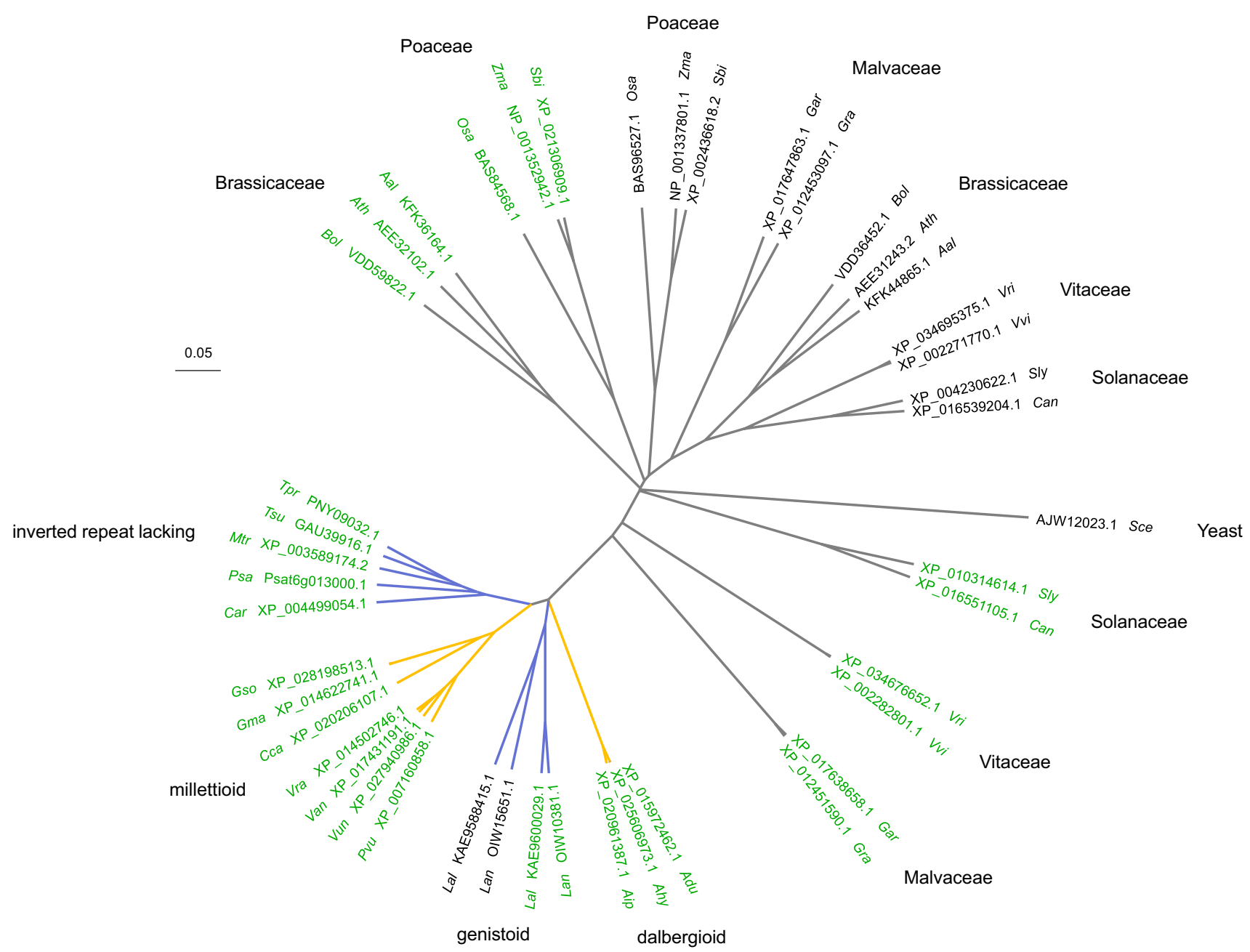

Fig. 2 Neighbour-joining phylogenetic tree depicting homology of the Trimethylguanosine Synthase1-like gene family in six angiosperm families and yeast (Saccharomyces cerevisiae). Taxa and protein accession IDs are coloured to differentiate eukaryotic (black) and plant-specific (green) homologues. Yellow and purple tree branches distinguish papilionoid clades typically comprising warm-season and cool-season legume species, respectively. Taxa abbreviations and protein accession IDs are fully described in Online Resource 2 three heterozygous G/A genotypes were produced. In all instances, the genotype of the SNP was consistent with the recombination of DArTseq markers adjacent to the efl locus on linkage group CxG_LG14 and perfectly correlated with the qualitative eft phenotype-derived marker (Online Resources 1 and 9). Finally, the SNP was perfectly predictive of $e f$ phenotype in 40 wild and 49 other domesticated narrow-leafed lupins (Online Resource 5). The rare homozygous A genotype was observed only in Chittick, Wandoo, and the original efl mutant $\mathrm{N} 4229$, which are the only narrow-leafed lupin accessions with the efl mutation (Cowling 1999). Perfect linkage of the unique transition mutation in Lup005529.1 with efl phenotype in three separate genetic and natural narrow-leafed lupin populations warranted further investigation of the plant-specific LanTGS1 homologue.

\section{Exploring impacts of a transition mutation on TGS1 protein function}

The full-length predicted CDS and translated protein sequences derived from Lup005529.1 were closely examined to establish all polymorphisms within the plant-specific LanTGSI homologue and determine if any, including the G/A SNP already under investigation, may explain phenotypic differences between $e f l$ and $E f l$ genotypes. A total of 14 SNPs and 10 unique CDS haplotypes were observed among 49 resequenced accessions (Fig. 3; Online Resource 11; MZ274313-MZ274322). Six of the 14 SNPs created nonsynonymous mutations in the translated protein sequences, including the candidate causal mutation for efl (i.e. the G/A transition unique to Chittick, Wandoo, and N4299), which led to an alanine/threonine substitution at amino acid residue 


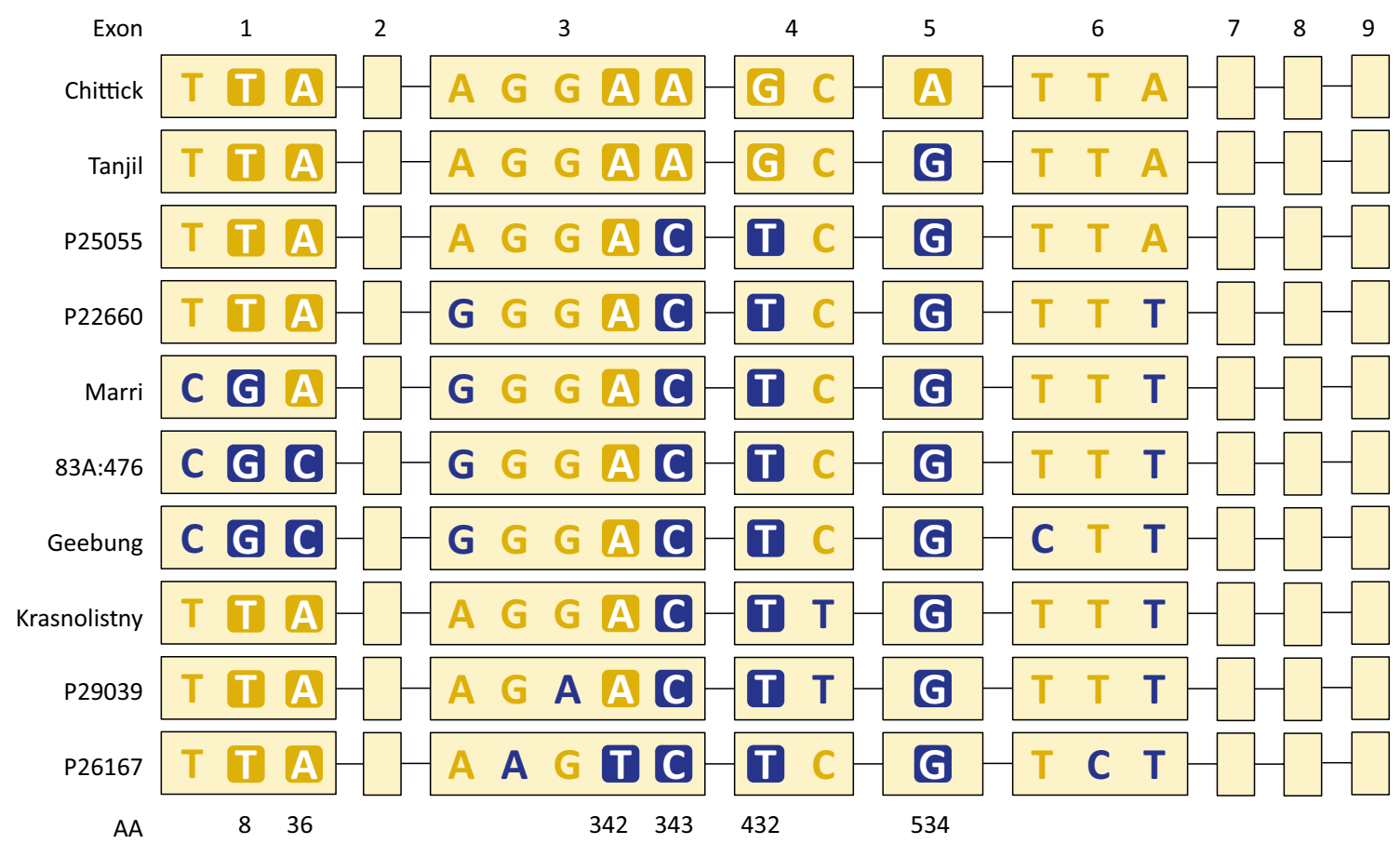

Fig. 3 Schematic illustration of the 10 unique single nucleotide polymorphism (SNP) haplotypes observed within the coding sequence (1815 nucleotides) of a plant-specific Trimethylguanosine Synthase1like (LanTGS1) homologue (Lup005529.1) in narrow-leafed lupin (Lupinus angustifolius L.). SNPs have been colour coded such that gold represents the Chittick-like ( $e f l$ ) genotype, while blue represents an alternative genotype. Background fills are used to highlight

534. Six unique protein sequences were translated from the CDS haplotypes. Importantly, all three narrow-leafed lupin accessions with the efl phenotype (Chittick, Wandoo, and N4229) shared the same CDS haplotype and translated protein sequence, which differed from that of Borre (the variety used to derive $e f l$ via mutagenesis) and the Tanjil reference genome only by the G/A SNP and associated alanine/threonine substitution (Online Resource 11).

Functional domains and conserved motifs were annotated in the six unique translated protein sequences to determine whether any of the non-synonymous substitutions had potentially compromised protein function. As described earlier, three protein domains were predicted, including (1) a WW domain (IPR001202; amino acids 297-326), (2) an RNA cap guanine-N2 methyltransferase domain (IPR019012; amino acids 541-695), and (3) an S-adenosyl-L-methionine-dependent methyltransferase (SAM MTase) superfamily domain (IPR029063; amino acids 503-660). The latter was the only domain affected by one of the six nonsynonymous mutations identified during haplotype analysis. Specifically, the SAM MTase domain overlapped residue 534, which was affected by the candidate causal SNP for ef $l$ (i.e. the G/A transition). An alanine residue was invariably conserved at this position in eukaryotic and plant-specific
SNPs that create non-synonymous mutations resulting in amino acid (AA) changes. The number beneath each non-synonymous SNP corresponds to the AA residue affected within the translated protein sequence. AA residue 534 corresponds to the Chittick haplotype which has a unique $\mathrm{G}$ to $\mathrm{A}$ mutation. The reference allele corresponds to the genotype presented in the Tanjil variety haplotype

TGS1 proteins in yeast and numerous diploid species from the papilionoid legume subfamily and five other angiosperm families (Fig. 4; Online Resource 12). The only observed substitution (alanine to threonine) at this location was in the translated sequence of the Chittick haplotype. The location of this substitution additionally corresponded with motif X, which represented one of nine classical motifs in the Class I SAM MTase superfamily that were annotated in the translated TGS1 sequences (Fig. 4; Online Resource 12; Fauman et al. 1999; Mouaikel et al. 2003).

3D models of the Tanjil ( $E f l)$ and Chittick (efl) translated sequences were constructed to assess the location of residue 534 relative to secondary and tertiary protein structures and determine whether the alanine/threonine substitution affected protein function. Both models featured classical Class I SAM MTase core folds (Martin and McMillan 2002), which consisted of alternating $\beta$ strands and $\alpha$ helices forming an overall twisted $\beta$ sheet structure (Fig. 5). Four $\alpha$ helices were located at the $\mathrm{N}$ terminal of the core fold forming a small subdomain. Additional secondary structures ( $\alpha 8, \alpha 10, \beta 5$, and $\beta 7$ ) were present within loops linking the central components of the $\beta$ sheet. Residue 534 was located within the first $\alpha$ helix $(\alpha 5)$ contributing to the central $\beta$ sheet structure (Figs. 4 and 5). This result was consistent 


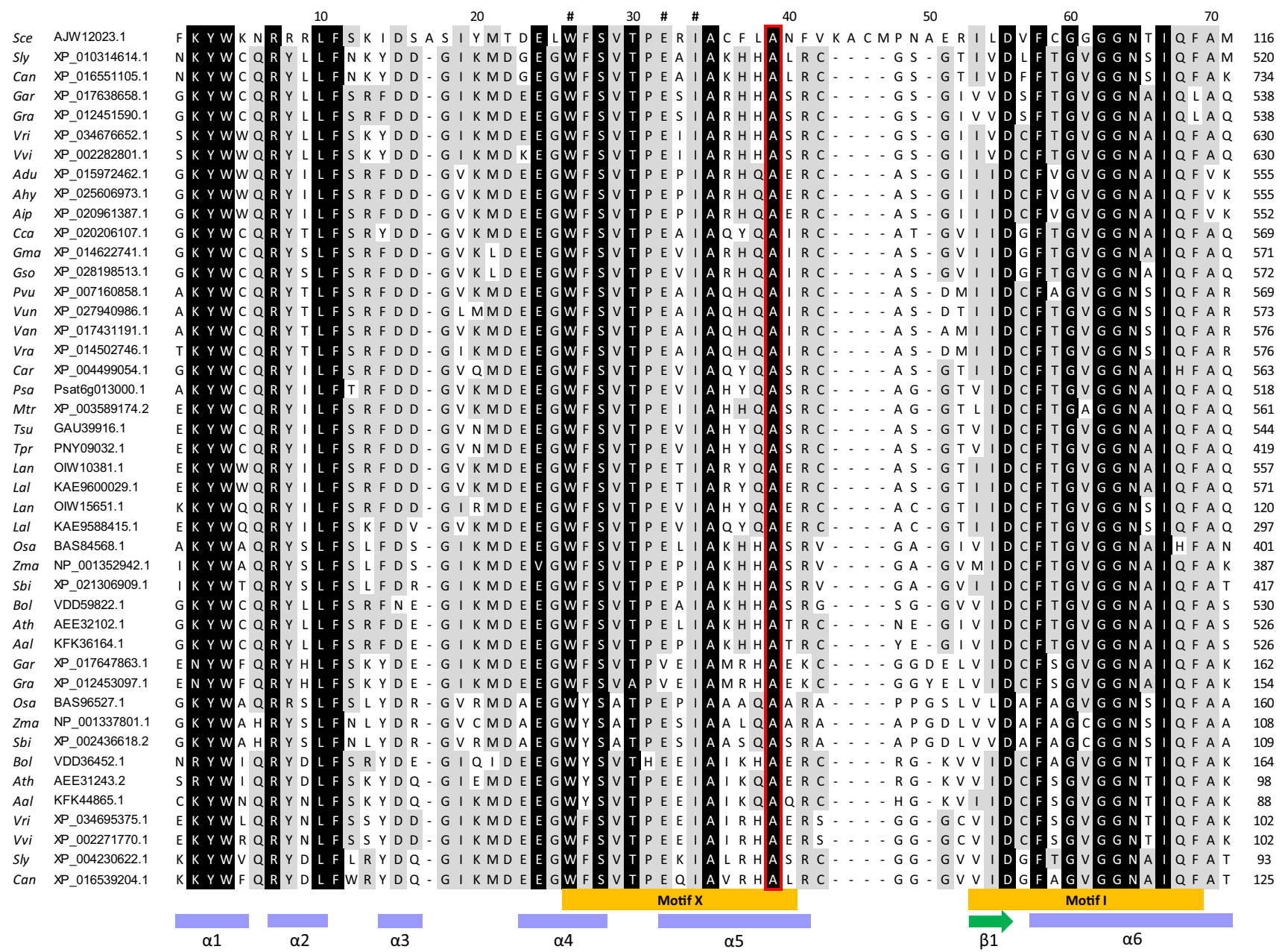

Fig. 4 Partial alignment of the S-adenosyl-L-methionine-dependent methyltransferase (SAM MTase) superfamily domain (IPR029063) within Trimethylguanosine Synthase1-like (TGS1) protein sequences from yeast (Saccharomyces cerevisiae) and 29 diploid angiosperms. Shading indicates perfectly (black) and highly ( $\geq 50 \%$; grey) conserved residues. Conserved motifs within the SAM MTase superfamily of proteins are labelled according to annotations from Mouaikel et al. (2003) and Fauman et al. (1999). Secondary protein structures are indicated by purple cylinders ( $\alpha$ helix) and green arrows $(\beta$ strands). A red box highlights an alanine residue which is substituted with threonine in the Chittick narrow-leafed lupin variety containing the efl mutation for facultative vernalisation requirement and midseason flowering. Residues with motif $X$ that have been experimentally mutated by Mouaikel et al. (2003) are marked by an "\#” symbol. Taxa abbreviations and protein accession IDs are fully described in Online Resource 2 with expectations for the structural placement of motif $\mathrm{X}$ in $\alpha$ helices within Class I MTase proteins (Fauman et al. 1999; Mouaikel et al. 2003). Motif X additionally encompassed part of the proceeding $\alpha$ helix ( $\alpha 4)$ and the loop connecting $\alpha 4$ and $\alpha 5$.

\section{Investigating the regulation of a candidate gene under vernalising and non-vernalising conditions}

Finally, we explored the expression of Lup005529.1 in leaves of Chittick and Geebung to learn more about its potential involvement in regulating flowering time within the vernalisation pathway. The relative abundance of Lup005529.1 transcript was unaffected by vernalisation treatment $(P=0.1347)$ and was stable across all five plant growth stages $(P=0.2028)$. Although the relative expression of Lup005529.1 was significantly higher in Geebung than in Chittick $(P=0.0119)$, the fold difference between $e f l$ and $E f l$ genotypes was minimal at all times (1.4-fold) (Online Resource 13). The absence of differential expression between parents complemented motif annotation results and was consistent with the hypothesis that the efl mutation impacted the function rather than the regulation of the plant-specific LanTGS1 gene. 


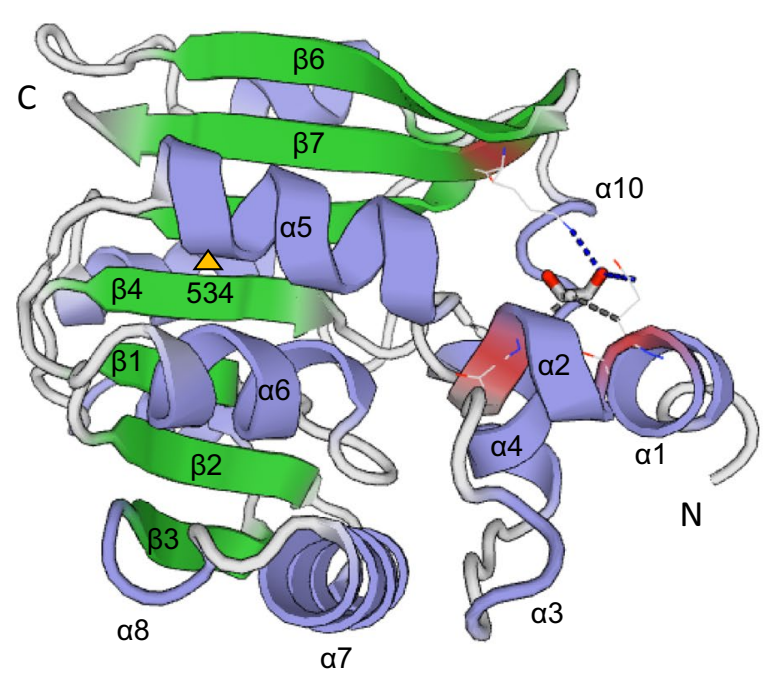

Front view

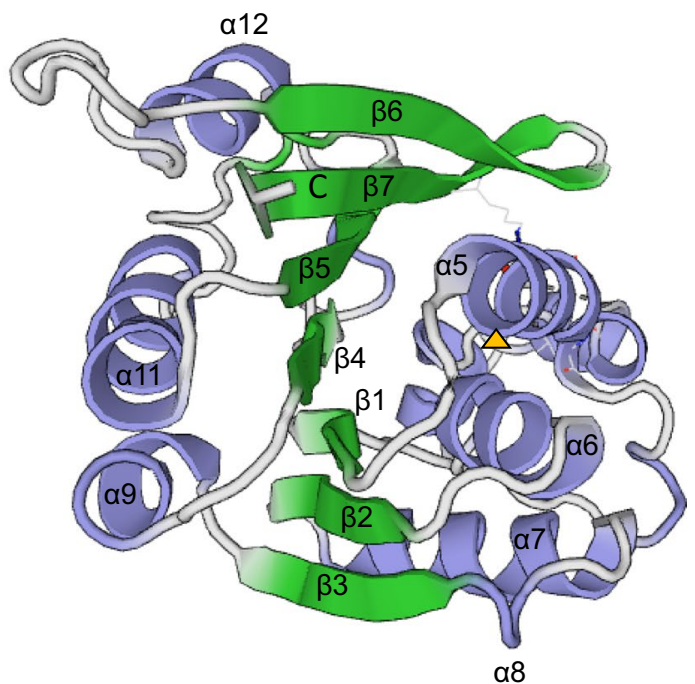

Side view
Fig. 5 a Front and b side views of the SWISS-MODEL predicted secondary and tertiary structure of the plant-specific Trimethylguanosine Synthase 1-like (TGS1) protein (OIW10381.1; 717 amino acids) in narrow-leafed lupin (Lupinus angustifolius L.). The model represents residues 493-696, which share homology to the human TGS1 template, 3dgh.1.A. Purple helices represent $\alpha$-helices and green

\section{Discussion}

The timing of flowering is a crucial adaptive trait affecting the reproductive fitness of wild plants and domesticated crops alike. Vernalisation is one of several important mechanisms used to regulate flowering time in species originating from temperate climates. The objective of this study was to explore the genetic basis and possible molecular role of the efl mutation within the vernalisation pathway of narrowleafed lupin; a Mediterranean winter-annual grain legume. Using 2314 DArTseq molecular markers, we produced a linkage map for an $F_{6}$ RIL population comprising 181 lines segregating for $e f l$ and which was rapidly progressed from the $F_{2}$ generation over a period of 13 months using an optimised aSSD method without bias towards early flowering (Croser et al. 2016). This linkage map adds to the growing number of genetic and genomic resources for this species (Singh et al. 2020) and will be useful for resolving inconsistencies in the physical assembly of the narrow-leafed lupin reference genome (Hane et al. 2017), particularly on pseudochromosome NLL-10, which represented $17 \%$ of the $781.2 \mathrm{cM}$ map (Table 1). Genetic mapping localised $e f$ to a 1.26 -cM interval on NLL-10 corresponding to a 267 $\mathrm{Kb}$ physical region within an improved genome assembly (Online Resource 7). A single promising candidate gene was identified within this region: a plant-specific TGS1 homologue, Lup005529.1. This is the first time a TGS1 orthologue has been linked to the vernalisation pathway and flowering arrows represent $\beta$-strands, which are numbered. An orange arrow is used to highlight an alanine/threonine substitution at amino acid residue 534, which co-segregates with the efl phenotype for mid-late season flowering time and is located within a motif (motif $\mathrm{X}$ ) involved in substrate binding

time control in plants and consequently represents an important finding.

A single G/A SNP within the plant-specific LanTGSI homologue was perfectly predictive of the efl phenotype in bi-parental mapping populations and diverse germplasm (Fig. 4; Online Resources 7 and 8). This polymorphism is consistent with mutations arising from ethylene imine treatment, where guanine DNA bases are preferentially alkylated, depurinated, and subsequently vulnerable to random and incorrect replacement with an alternative base during replication of single-stranded DNA (Verschaeve and KirschVolders 1990). Importantly, the SNP was found to create a non-synonymous mutation within a well-conserved motif (motif X) in the SAM MTase protein domain. An alanine residue was perfectly conserved in the eukaryotic and plantspecific TGS1 homologues of 17 papilionoid legumes, 12 diploid species from five other angiosperm families as well as yeast. In stark contrast, the translated plant-specific TGS1 sequence of Chittick (efl) had a threonine at residue 534. Together with an absence of differential expression of Lup005529.1 between Chittick and Geebung, this observation strongly suggested that the substitution arising from the G/A SNP may have altered protein function.

Experimental confirmation that the alanine/threonine substitution in motif $X$ alters the plant-specific LanTGS1 protein function was beyond the scope of this current study; however, functional characterisation of mutations in motif $\mathrm{X}$ has previously been performed in yeast (Mouaikel et al. 
2003). In yeast, ScTGS1 is responsible for post-transcriptional maturation of snRNA and snoRNAs cap structures, which it achieves by hypermethylating the $\mathrm{m}^{7} \mathrm{G}$ cap of these RNA species to $m_{3} G$ (i.e. trimethylguanosine) caps. The mature snRNA and snoRNAs then go on to play roles in processing immature mRNA and rRNAs, respectively. Knockout and loss-of-function mutations in SceTGS1 inhibit the hypermethylation and correct splicing of immature snRNA and snoRNA, which manifests in a cold-sensitive phenotype and abnormal development under cool temperature (Mouaikel et al. 2002). A similar sensitivity to cold ambient temperature and defects to vegetative and reproductive organs result from mutations in the plant-specific AthTGS1 homologue in Arabidopsis (Gao et al. 2017). Mouaikel et al. (2003) demonstrated that the $\alpha$ helix structure containing motif $X$ participates in forming the $\mathrm{m}^{7} \mathrm{G}$ cap substrate binding pocket of SceTGS1 by targeted substitution of isoleucine for arginine at residue 175 (one of three residues assessed within motif $X$, as indicated in Fig. 4). This substitution prevented restoration of normal development in Scetgsl lossof-function mutants and was correlated with the absence of $m_{3} G$ cap structures in snRNAs and snoRNAs. Mouaikel et al. (2003) proposed that the side chain associated with arginine physically blocked the binding site for $\mathrm{m}^{7} \mathrm{G}$ caps and therefore inhibited methyltransferase activity of the mutated Scetgs 1 protein. Further research will be required to determine whether the alanine/threonine substitution at residue 534 follows precedent and similarly affects the methyltransferase activity of the plant-specific LanTGS1 protein and, as a result, affects vernalisation requirement and flowering time.

It remains unclear exactly how ef affects the vernalisation response in narrow-leafed lupin. The mutation was originally proposed to reduce the requirement for vernalisation (Gladstones 1977, 1982). Subsequent research by Landers (1995) indicated this was achieved through the creation of a facultative rather than obligate requirement for vernalisation. However, the same study also brought into question whether efl may instead increase the temperature threshold at which vernalisation operates. White lupin (L. albus) sets precedence for such a mechanism as plant development in selected vernalisation-responsive genotypes (e.g. variety Ultra) is reportedly accelerated under temperatures as high as $17{ }^{\circ} \mathrm{C}$ in as little as 10 days (Clapham and Willcott 1995; Huyghe 1991). The identification of Lup005529.1 as a candidate gene for efl may offer further support for this latter hypothesis, as mutations in TGS1 affect thresholds at which development is impaired during cold treatment. For example, Arabidopsis tgs 1 mutants develop minor defects in their leaves and flowers when grown at $10{ }^{\circ} \mathrm{C}$ but develop more severe abnormalities that inhibit viable seed production at $5{ }^{\circ} \mathrm{C}$ (Gao et al. 2017). Similarly, yeast $\operatorname{tgs} 1$ mutants are able to grow, albeit slowly, at $23{ }^{\circ} \mathrm{C}$ but are fully incapable of doing so once ambient temperature is reduced to $16{ }^{\circ} \mathrm{C}$ (Mouaikel et al. 2002).

There are positive implications for narrow-leafed lupin pre-breeding should $e f l$ indeed reduce the temperature and/ or duration threshold at which vernalisation is satisfied in this species. Early flowering, vernalisation-unresponsive varieties with the $K u$ and $J u l$ alleles are now almost exclusively sown for all agricultural grain production in Australia and Northern Europe. However, the dominance of both alleles over most other genetic variation for flowering time (Boersma 2007) and the central role of their underlying gene (LanFTcl) within the genetic network for floral initiation reduces the ability for breeders to manage other minor alleles for phenology in the absence of marker-assisted selection. In fact, the efl mutation would not have been discovered if the mutation occurred in a $K u$ or $J u l$ variety due to their dominant early flowering genotypes. Late-flowering $k u$ varieties of narrow-leafed lupin require a strong vernalisation period which may not be met every season, at least within mild winter climates. The milder facultative vernalisation requirement of efl varieties could be a major advantage in such situations. Alternatively, new mutations within Lup005529.1 via gene editing or TILLING may enable the temperature threshold for vernalisation to be sufficiently increased such that $k u$ varieties are better adapted to warmer climates. This would ultimately create an opportunity for other flowering time loci to be integrated in breeding and establish a wider range of phenologies in elite varieties.

As the candidate SNP was exclusively associated with the efl phenotype in this study, it is now possible for a perfect molecular marker to be designed for future genotypic selection (marker-assisted selection) of efl within breeding programmes. Genotypic selection would greatly facilitate selection for subtle flowering time alleles, such as efl, which are at risk of being lost during the early stages of phenotypic selection due to their recessive inheritance, particularly if breeding lines are evaluated in environments or seasons where these alleles do not provide an adaptive advantage.

Supplementary Information The online version contains supplementary material available at https://doi.org/10.1007/s00122-021-03910-2.

Acknowledgements This research was generously funded by a subcontract of grant DAW00238 from the Grains Research and Development Corporation (GRDC) to The University of Western Australia, with additional support from The University of Western Australia. Seed was kindly provided for Borre, Wandoo, and N4229 by the Australian Grains Genebank (Horsham, Victoria). We thank Dr Andrzej Killian (Diversity Arrays Technology Pty Ltd) for his assistance throughout this project, and Prof Patrick Finnegan for constructive feedback on this manuscript. Our sincere thanks go to Ms Simone Wells, Ms Sabrina Tschirren, Ms Lynette Taylor and Dr Mahsa Mousavi-Derazmahalleh for their technical assistance and to Mr Robert Creasy and Mr Bill Piasini for their glasshouse expertise. Lastly, CMT wishes to sincerely 
thank Dr Armin Scheben and Dr Philipp Bayer for informative discussions and advice about linkage/QTL mapping software.

Author contribution statement This study was conceived by CMT, MNN, LGK, JDB, and WAC. Development of the experimental populations was undertaken by CMT, FMR, JSC, WAC, MNN, LGK, and JDB. Phenotyping, genotyping, and bioinformatic analyses were completed by CMT, LGK, GG, KS, and MNN. Linkage mapping was performed by MNN and CMT. Gene expression analyses were completed by CMT, and protein modelling/characterisation was performed by GG, LGK, and CMT. All authors contributed to the writing and/or editing of the manuscript and approve the final version of the manuscript.

Funding This research was generously funded by a subcontract of grant DAW00238 from the Grains Research and Development Corporation (GRDC) to The University of Western Australia, with additional support from The University of Western Australia.

Data availability All data relating to this study are freely available within the Supplementary Information and upon request to the corresponding author. gDNA and protein sequences have been deposited to NCBI repositories, including GenBank and SRA archives, and accession numbers are provided within text. Seed produced from the $F_{6}$ RIL population in this study have been deposited into the Australian Grains Genebank (AGG), Horsham, Victoria.

\section{Declarations}

Conflict of interest MNN is an editor for TAG. The authors declare no other conflicts of interest.

Open Access This article is licensed under a Creative Commons Attribution 4.0 International License, which permits use, sharing, adaptation, distribution and reproduction in any medium or format, as long as you give appropriate credit to the original author(s) and the source, provide a link to the Creative Commons licence, and indicate if changes were made. The images or other third party material in this article are included in the article's Creative Commons licence, unless indicated otherwise in a credit line to the material. If material is not included in the article's Creative Commons licence and your intended use is not permitted by statutory regulation or exceeds the permitted use, you will need to obtain permission directly from the copyright holder. To view a copy of this licence, visit http://creativecommons.org/licenses/by/4.0/.

\section{References}

ABARE (2018) Australian crop report, No. 188, December 2018. Australian Bureau of Agricultural and Resource Economics and Sciences, Canberra, Australia.

Berger JD, Buirchell BJ, Luckett DJ, Nelson MN (2012a) Domestication bottlenecks limit genetic diversity and constrain adaptation in narrow-leafed lupin (Lupinus angustifolius L.). Theor Appl Genet 124:637-652. https://doi.org/10.1007/s00122-011-1736-z

Berger JD, Buirchell BJ, Luckett DJ, Palta JA, Ludwig C, Liu DL (2012b) How has narrow-leafed lupin changed in its 1 st 40 years as an industrial, broad-acre crop? A G $\times$ E-based characterization of yield-related traits in Australian cultivars. Field Crops Res 126:152-164. https://doi.org/10.1016/j.fcr.2011.10.006

Boersma JG (2007) Contributions to the molecular genetics of the narrow-leaf Lupin (Lupinus angustifolius L.) - mapping, maker development and QTL analysis. PhD Thesis. The University of Western Australia, Perth, Australia

Bouché F, Woods DP, Amasino RM (2017) Winter memory throughout the plant kingdom: different paths to flowering. Plant Physiol 173:27. https://doi.org/10.1104/pp.16.01322

Broman KW, Wu H, Sen S, Churchill GA (2003) R/qtl: QTL mapping in experimental crosses. Bioinformatics 19:889-890. https://doi. org/10.1093/bioinformatics/btg112

Chen C, Fletcher A, Lawes R, Berger J, Roberston M (2017) Modelling phenological and agronomic adaptation options for narrow-leafed lupins in the southern grainbelt of Western Australia. Eur J Agron 89:140-147. https://doi.org/10.1016/j.eja.2017.05.005

Chen L, Roake CM, Galati A, Bavasso F, Micheli E, Saggio I, Raffa GD (2020) Loss of human TGS1 hypermethylase promotes increased telomerase RNA and telomere elongation. Cell Rep 30:1358-1372.e1355. https://doi.org/10.1016/j.celrep.2020.01.004

Clapham WM, Willcott JB (1995) Thermosensitivity in spring white lupin. Ann Bot 76:349-357. https://doi.org/10.1006/anbo.1995. 1107

Colono C, Ortiz JPA, Permingeat HR, Canada EDS, Siena LA, Spoto N, Pessino SC (2019) A plant-specific TGS1 homolog influences gametophyte development in sexual tetraploid Paspalum notatum ovules. Front Plant Sci 10:1566. https://doi.org/10.3389/fpls.2019. 01566

Cowling WA (1999) Pedigrees and characteristics of narrow-leafed lupin cultivars released in Australia from 1967 to 1998. Western Australian Department of Agriculture, Bulletin 4365. South Perth, Australia

Cowling WA (2020) Genetic diversity in narrow-leafed lupin breeding after the domestication bottleneck. In: Singh KB, Kamphuis LG, Nelson MN (eds) The lupin genome. Springer Nature, Cham, Switzerland, pp 1-17. https://doi.org/10.1007/ 978-3-030-21270-4_1

Cowling WA, Wood PM (1989) Resistance to Phomopsis stem and pod blight of narrow-leafed lupin in a range of environments and its association with reduced Phomopsis infection. Aust J Exp Agric 29:43-50. https://doi.org/10.1071/EA9890043

Cowling WA, Allen JG, Wood PM (1988) Resistance to Phomopsis stem blight reduces the lupinosis toxicity of narrow-leafed lupin stems. Aust J Exp Agric 28:195-202. https://doi.org/10.1071/ EA9880195

Cowling WA, Hamblin J, Wood PM, Gladstones JS (1987) Resistance to Phomopsis stem blight in Lupinus angustifolius L. Crop Sci 27:648-652. https://doi.org/10.2135/cropsci1987.0011183X00 $2700040007 \mathrm{x}$

Croser JS, Pazos-Navarro M, Bennett RG, Tschirren S, Edwards K, Erskine W, Ribalta FM (2016) Time to flowering of temperate pulses in vivo and generation turnover in vivo-in vitro of narrowleafed lupin accelerated by low red to far-red ratio and high intensity in the far-red region. Plant Cell Tissue Organ Cult 127:591599. https://doi.org/10.1007/s11240-016-1092-4

Doyle JJ, Doyle JL (1990) Isolation of plant DNA from fresh tissue. Focus 12:13-15

Dracup M, Kirby EJM (1996) Lupin development guide. University of Western Australia Press, Nedlands, Western Australia

Fauman EB, Blumenthal RM, Cheng X (1999) Structure and evolution of adomet-dependent methyltransferases. In: Cheng X, Blumenthal RM (eds) S-adenosylmethionine-dependent methyltransferases: structures and functions. World Scientific Publishing Co Pte Ltd, Singapore, pp 1-38. https://doi.org/10.1142/9789812813 077_0001

Gao J, Wallis JG, Jewell JB, Browse J (2017) Trimethylguanosine Synthase 1 (TGS1) is essential for chilling tolerance. Plant Physiol 174:1713. https://doi.org/10.1104/pp.17.00340

Gendall AR, Levy YY, Wilson A, Dean C (2001) The VERNALIZATION 2 gene mediates the epigenetic regulation of vernalization 
in Arabidopsis. Cell 107:525-535. https://doi.org/10.1016/S00928674(01)00573-6

Girard C, Verheggen C, Neel H, Cammas A, Vagner S, Soret J, Bordonné R (2008) Characterization of a short isoform of human Tgs1 hypermethylase associating with small nucleolar ribonucleoprotein core proteins and produced by limited proteolytic processing. J Biol Chem 283:2060-2069. https://doi.org/10.1074/ jbc.M704209200

Gladstones JS (1970) Lupins as crop plants. Field Crop Abstracts 23:123-148

Gladstones JS (1977) The narrow-leafed lupin in Western Australia. Western Australia Department of Agriculture, Bulletin 3990. South Perth, Australia.

Gladstones JS (1982) Register of lupin cultivars (b) Lupinus angustifolius L. (narrow-leafed lupin) cv. Chittick (Reg. No. b-10). J Aust I Agr Sci 48:122-124

Gladstones JS, Hill GD (1969) Selection for economic characters in Lupinus angustifolius and $L$. digitatus. 2. Time of flowering. Aust J Exp Agric Anim Husb 9:213-220. https://doi.org/10.1071/ EA9690213

Griffiths A, Miller J, Suzuki D, Lewontin R, Gelbart W (2000) An introduction to genetic analysis. 7th edn. W H Freeman, New York

Hane JK, Ming Y, Kamphuis LG, Nelson MN, Garg G, Atkins CA, Singh KB (2017) A comprehensive draft genome sequence for lupin (Lupinus angustifolius), an emerging health food: insights into plant-microbe interactions and legume evolution. Plant Biotechnol J 15:318-330. https://doi.org/10.1111/pbi.12615

Harries M, Anderson GC, Hüberli D (2015) Crop sequences in Western Australia: what are they and are they sustainable? Findings of a four-year survey. Crop Pasture Sci 66:634-647. https://doi. org/10.1071/CP14221

Hecht V, Foucher F, Ferrándiz C, Macknight R, Navarro C, Morin J, Weller J (2005) Conservation of Arabidopsis flowering genes in model legumes. Plant Physiol 137:1420-1434. https://doi.org/ 10.1104/pp.104.057018

Hecht V, Laurie RE, Vander Schoor JK, Ridge S, Knowles CL, Liew LC, Weller JL (2011) The pea GIGAS gene is a FLOWERING LOCUS T homolog necessary for graft-transmissible specification of flowering but not for responsiveness to photoperiod. Plant Cell 23:147. https://doi.org/10.1105/tpc.110.081042

Hondelmann W (1984) The lupin-ancient and modern crop plant. Theor Appl Genet 68:1-9. https://doi.org/10.1007/BF00252301

Huyghe C (1991) Winter growth of autumn-sown white lupin (Lupinus albus L.): main apex growth model. Ann Bot 67:429-434. https://www.jstor.org/stable/42764367

Jaudal M, Yeoh CC, Zhang L, Stockum C, Mysore KS, Ratet P, Putterill J (2013) Retroelement insertions at the Medicago FTal locus in spring mutants eliminate vernalisation but not long-day requirements for early flowering. Plant J 76:580-591. https:// doi.org/10.1111/tpj.12315

Jaudal M, Zhang L, Che C, Hurley D, Thomson G, Wen J, Putterill J (2016) MtVRN2 is a polycomb VRN2-like gene which represses the transition to flowering in the model legume Medicago truncatula. Plant J 86:145-160. https://doi.org/10.1111/tpj.13156

Jung C-H, Wong CE, Singh MB, Bhalla PL (2012) Comparative genomic analysis of soybean flowering genes. PLoS One 7:e38250. https://doi.org/10.1371/journal.pone.0038250

Kamphuis LG, Hane JK, Nelson MN, Gao L, Atkins CA, Singh KB (2015) Transcriptome sequencing of different narrow-leafed lupin tissue types provides a comprehensive uni-gene assembly and extensive gene-based molecular markers. Plant Biotechnol J 13:14-25. https://doi.org/10.1111/pbi.12229

Lambers H, Clements JC, Nelson MN (2013) How a phosphorusacquisition strategy based on carboxylate exudation powers the success and agronomic potential of lupines (Lupinus,
Fabaceae). Am J Bot 100:263-288. https://doi.org/10.3732/ ajb.1200474

Landers KF (1995) Vernalization responses in narrow-leafed lupin (Lupinus angustifolius) genotypes. Aust J Agric Res 46:10111025. https://doi.org/10.1071/AR9951011

Langmead B, Salzberg SL (2012) Fast gapped-read alignment with Bowtie 2. Nat Meth 9:357-359. https://doi.org/10.1038/nmeth. 1923

Laurie RE, Diwadkar P, Jaudal M, Zhang L, Hecht V, Wen J, Macknight RC (2011) The Medicago FLOWERING LOCUS T homolog, MtFTa1, is a key regulator of flowering time. Plant Physiol 156:2207-2224. https://doi.org/10.1104/pp.111.180182

Li H, Handsaker B, Wysoker A, Fennell T, Ruan J, Homer N, Subgroup GPDP (2009) The sequence alignment/map format and SAMtools. Bioinformatics 25:2078-2079. https://doi.org/10.1093/bioinforma tics/btp352

Lucas MM, Stoddard F, Annicchiarico P, Frias J, Martinez-Villaluenga C, Sussmann D, Pueyo J (2015) The future of lupin as a protein crop in Europe. Front Plant Sci 6:705. https://doi.org/10.3389/ fpls.2015.00705

Martin JL, McMillan FM (2002) SAM (dependent) I AM: the S-adenosylmethionine-dependent methyltransferase fold. Curr Opin Struct Biol 12:783-793. https://doi.org/10.1016/S0959-440X(02) 00391-3

Martin M (2011) Cutadapt removes adapter sequences from highthroughput sequencing reads. EMBnet J 17(1):10-12

Mikołajczyk J (1966) Genetic studies in Lupinus angustifolius. Part. III. Inheritance of the alkaloid content, seed hardness and length of the growing season in blue lupin. Genetica Polonica 7:181-196

Mouaikel J, Bujnicki JM, Tazi J, Bordonné R (2003) Sequence-structure-function relationships of Tgs1, the yeast snRNA/snoRNA cap hypermethylase. Nucleic Acids Res 31:4899-4909. https:// doi.org/10.1093/nar/gkg656

Mouaikel J, Verheggen C, Bertrand E, Tazi J, Bordonné R (2002) Hypermethylation of the cap structure of both yeast snRNAs and snoRNAs requires a conserved methyltransferase that is localized to the nucleolus. Mol Cell 9:891-901. https://doi.org/10.1016/ S1097-2765(02)00484-7

Mousavi-Derazmahalleh M, Bayer P, Nevado B, Hurgobin B, Filatov D, Kilian A, Nelson M (2018) Exploring the genetic and adaptive diversity of a pan-Mediterranean crop wild relative: narrow-leafed lupin. Theor Appl Genet 131:887-901. https://doi.org/10.1007/ s00122-017-3045-7

Nelson MN, Berger JD, Erskine W (2010) Flowering time control in annual legumes: prospects in a changing global climate. CAB Rev Perspect Agric Vet Sci Nutr Nat Resour 5:017. https://doi.org/10. 1079/pavsnnr20105017

Nelson MN, Książkiewicz M, Rychel S, Besharat N, Taylor CM, Wyrwa K, Wolko B (2017) The loss of vernalization requirement essential to domestication in narrow-leafed lupin is associated with a deletion in the promoter and de-repressed expression of an FT homologue. New Phytol 213:220-232. https://doi.org/10. 1111/nph.14094

Ortega R, Hecht VFG, Freeman JS, Rubio J, Carrasquilla-Garcia N, Mir RR, Weller JL (2019) Altered expression of an FT cluster underlies a major locus controlling domestication-related changes to chickpea phenology and growth. Front Plant Sci 10:824. https:// doi.org/10.3389/fpls.2019.00824

Rahman MS, Gladstones JS (1972) Control of lupin initiation by vernalization, photoperiod and temperature under controlled environment. Aust J Exp Agric Anim Husb 12:638-645. https://doi.org/ 10.1071/EA9720638

Ream TS, Woods DP, Amasino RM (2012) The molecular basis of vernalization in different plant groups. Cold Spring Harbor Symp Quant Biol 77:105-115. https://doi.org/10.1101/sqb.2013.77. 014449 
Rychel S, Książkiewicz M, Tomaszewska M, Bielski W, Wolko B (2019) FLOWERING LOCUS T, GIGANTEA, SEPALLATA, and FRIGIDA homologs are candidate genes involved in white lupin (Lupinus albus L.) early flowering. Mol Breed 39:43. https://doi. org/10.1007/s11032-019-0952-0

Sansaloni C, Petroli C, Jaccoud D, Carling J, Detering F, Grattapaglia D, Kilian A (2011) Diversity Arrays Technology (DArT) and next-generation sequencing combined: genome-wide, high throughput, highly informative genotyping for molecular breeding of Eucalyptus. BMC Proc 5:P54. https://doi.org/10.1186/ 1753-6561-5-s7-p54

Siena LA, Ortiz, JPA, Olivier L, Pessino S (2014) PnTgs 1-like expression during reproductive development supports a role for RNA methyltransferases in the aposporous pathway. BMC Plant Biol 14:297

Singh KB, Foley RC, Garg G, Kamphuis LG (2020) Overview of genomic resources available for lupins with a focus on narrow-leafed lupin (Lupinus angustifolius). In: Singh KB, Kamphuis LG, Nelson MN (eds) The lupin genome. Springer Nature, Cham, Switzerland, pp 31-43. https://doi.org/10.1007/ 978-3-030-21270-4_3

Solovyev V, Kosarev P, Seledsov I, Vorobyev D (2006) Automatic annotation of eukaryotic genes, pseudogenes and promoters. Genome Biol 7:S10. https://doi.org/10.1186/gb-2006-7-s1-s10

Taylor C, Jost R, Erskine W, Nelson M (2016) Identifying stable reference genes for qRT-PCR normalisation in gene expression studies of narrow-leafed lupin (Lupinus angustifolius L.). PLoS One 11:e0148300

Taylor CM, Kamphuis LG, Cowling WA, Berger JD, Nelson MN (2020a) Genomic applications and resources to dissect flowering time control in narrow-leafed lupin. In: Singh KB, Kamphuis
LG, Nelson MN (eds) The lupin genome. Springer Nature, Cham, Switzerland, pp 109-138. https://doi.org/10.1007/ 978-3-030-21270-4_9

Taylor CM, Kamphuis LG, Cowling WA, Nelson MN, Berger JD (2020b) Ecophysiology and phenology: genetic resources for genetic/genomic improvement of narrow-leafed lupin. In: Singh KB, Kamphuis LG, Nelson MN (eds) The lupin genome. Springer Nature, Cham, Switzerland, pp 19-30. https://doi.org/10.1007/ 978-3-030-21270-4_2

Taylor CM, Kamphuis LG, Zhang W, Garg G, Berger JD, MousaviDerazmahalleh M, Nelson MN (2019) INDEL variation in the regulatory region of the major flowering time gene $L a n F T c 1$ is associated with vernalization response and flowering time in narrow-leafed lupin (Lupinus angustifolius L.). Plant Cell Environ 42:174-187. https://doi.org/10.1111/pce.13320

Taylor J, Butler D (2017) R package ASMap: efficient genetic linkage map construction and diagnosis. J Stat Softw 79(6):1-29. https:// doi.org/10.18637/jss.v079.i06

Verschaeve L, Kirsch-Volders M (1990) Mutagenicity of ethyleneimine. Mutat Res 238:39-55. https://doi.org/10.1016/01651110(90)90038-D

Wurth L, Gribling-Burrer A-S, Verheggen C, Leichter M, Takeuchi A, Baudrey S, Allmang C (2014) Hypermethylated-capped selenoprotein mRNAs in mammals. Nucleic Acids Res 42:8663-8677. https://doi.org/10.1093/nar/gku580

Publisher's Note Springer Nature remains neutral with regard to jurisdictional claims in published maps and institutional affiliations. 